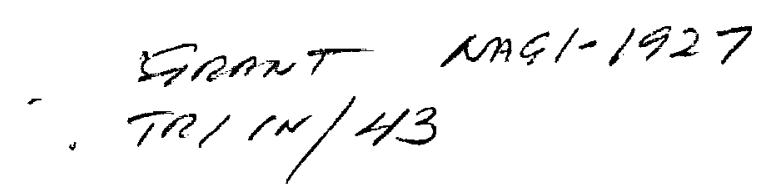

\title{
A Comparison of GPS and Scatterometer Sensing of Ocean Wind Speed and Direction
}

\author{
Michael Armatys ${ }^{1}$, Attila Komjathy ${ }^{1}$, Penina Axelrad ${ }^{1}$, Stephen J. Katzberg ${ }^{2}$ \\ ${ }^{1}$ CCAR/University of Colorado, Campus Box 431, Boulder, CO 80309 \\ ${ }^{2}$ NASA Langley Research Center, Code 328, Hampton, VA 23681 \\ 303-492-3489 (P) / 303-492-2825 (F) / armatys@colorado.edu
}

\begin{abstract}
Initial estimates of ocean surface wind speed and direction based on observations of reflected GPS signals are presented and compared to QuikSCAT wind fields. The two wind speed estimates are generally in agreement to within $2-3 \mathrm{~m} / \mathrm{s}$, and under favorable conditions of well developed seas and stable winds, direction estimates agree to within $10 \mathrm{deg}$. An overview of the GPS technique is presented as well as a presentation and discussion of these first results.
\end{abstract}

\section{INTRODUCTION}

In 1996, NASA researchers Stephen J. Katzberg and James L. Garrison identified the potential application of the Global Positioning System (GPS) to remote sensing of ocean surface conditions $[1,2]$. Their concept was to use GPS in a bistatic radar configuration with the GPS satellite transmitting an L-Band spread spectrum signal, and the receiver on an aircraft or spacecraft platform measuring the reflected signal characteristics. Since then, Katzberg and Garrison have continued to investigate the properties of the ocean-reflected GPS signals and have developed a specialized Delay-Mapping GPS receiver (DMR) to measure the reflected signals $[1,3]$. Using the DMR and geophysical models to predict the interaction of the GPS signals with sea water, researchers have been able to estimate wind speeds on the ocean surface with an accuracy of $2 \mathrm{~m} / \mathrm{s}$ [1]. Recently we have developed a new approach that extends the GPS-based wind retrieval to determination of wind direction as well as wind speed, based on measurements from two or more reflected GPS signals [3]. To validate the performance of GPS for wind vector retrieval we have previously relied on buoy data and wind speed estimates from TOPEX $\backslash$ POSEIDON [4].

This paper describes our first comparisons to wind vectors derived from the SeaWinds scatterometer onboard QuikSCAT. Ku-Band scatterometers represent the current state-of-the-art in sea surface wind remote sensing, providing highly accurate measurements with good temporal and spatial resolution on a global scale. The QuikSCAT science team provides a variety of wind products including wind vector maps at $25 \mathrm{~km}$ resolution. Nominal accuracy for the QuikSCAT wind vectors is 2 $\mathrm{m} / \mathrm{s}$ and $20 \mathrm{deg}$ for wind speed and direction, respectively. Performance is somewhat worse for wind speeds below 3 $\mathrm{m} / \mathrm{s}$, for grid points within $25 \mathrm{~km}$ of land, and for points very close to nadir or at large look angles. Algorithms are included in the QuikSCAT data reduction that resolve wind direction ambiguities and corresponding wind speed estimates. QuikSCAT observations provide a snapshot of the ocean surface conditions at the time of the satellite overflight. The backscatter measurements at Ku-Band are sensitive to rapid changes in the surface conditions making this a powerful sensor for wind retrieval. Because of the substantially different mechanisms for forward scattered L-Band reflections, the measurement and retrieval of wind vectors from GPS may provide a very useful complement to scatterometer observations in improving global wind observations and models.

\section{GPS-BASED WIND ESTIMATION}

As presented in [1, 2, 3], GPS-based wind retrievals rely on the modification of the correlation function for signals reflected by rough surfaces. The basic observable is not the pseudorange or carrier phase measurement used for most GPS applications, but rather a measure of the correlation of the reflected signal with a delayed replica of the PRN code. The distribution of this function over delays (and Dopplers) provides a mapping of the reflecting surface. In particular we use a model developed by $\mathrm{Za}$ vorotny and Voronovich $(\mathrm{Z}-\mathrm{V})[5,6]$ for prediction of the reflected signal structure. The $\mathrm{Z}-\mathrm{V}$ model embodies the forward-scatter radar equation with the geometric optics limit of the Kirchhoff Approximation. The distribution of ocean surface slopes is assumed to be Gaussian with variances determined by a wave spectra model such as that developed by Elfouhaily et al. [7]. These slope statistics define the shape and orientation of the glistening zone over which GPS signals are reflected toward the receiving antenna. The models currently used predict the maximum variance in the $u p /$ down-wind direction and minimum variance in the cross-wind direction. This allows for the identification of wind direction with a $180 \mathrm{deg}$ ambiguity. More advanced models that include up/downwind asymmetry due to effects such as Bragg scattering are currently under development.

To estimate wind vectors from GPS observations we first determine the surface slope statistics in the model which best fit the data. The second step is to use an ocean model to retrieve a wind speed and direction estimate from the slopes. Two satellites are necessary to recover the directional information lost in measuring the return from the entire annulus of the glistening zone with the DMR. In the current implementation, we try to use satellites with relatively high elevation angles to insure that the specular points are nearly co-located and that the elevation 
returns around this region may have been due to thicker, first year ice conditions (dark line).

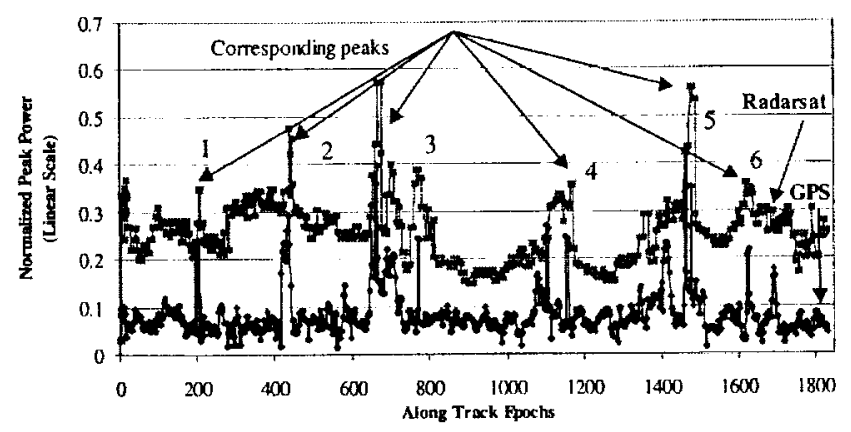

Figure 3. Normalized signal power for PRN 30.

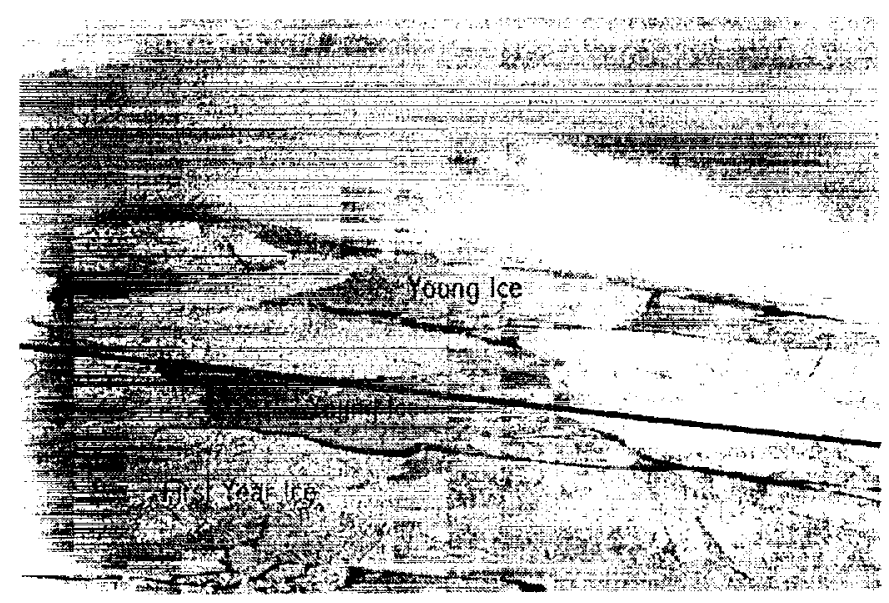

Figure 4. Photo taken from the aircraft in the vicinity of Label 5 showing black and darker gray areas of newly formed leads, new and young ice.

\section{CONCLUSIONS}

Field experiments, including data acquired from aircraft flights over the ice pack near Barrow, Alaska, suggest that the reflected GPS signals contain useful information over sea ice. Given this new potential application for GPS remote sensing, an effort to investigate reflected GPS signals over sea ice is discussed in the paper. A combination of modeling considerations, in-situ measurements and aircraft observations have been presented to quantify the theoretical and observed relationships between reflected GPS signals and cryospheric conditions.

\section{ACKNOWLEDGMENTS}

The research was funded by NASA Langley Research Center (LaRC) under grant no. NAG-1-1927. Thanks are due to A. Ulak of NIC for provision of ice reconnaissance information. RADARSAT data were obtained from NIC and the Alaska SAR Facility.

\section{REFERENCES}

[1] J.L. Garrison, S.J. Katzberg, and C.T. Howell, "Detection of ocean reflected GPS signals: theory and experiment," In the Proceedings of the IEEE Southeastcon 1997, Blacksburg, USA, pp. 290-294, 12-14 April 1997.

[2] J.L. Garrison, S.J. Katzberg, and M.I. Hill, "Effect of sea roughness on bistatically scattered range coded signals from the Global Positioning System," Geophys. Res. Letters, Vol. 25, No. 13, pp. 2257-2260, 1998.

[3] S.J. Katzberg and J.L Garrison "Utilizing GPS to determine ionospheric delay over the ocean," NASA Tech. Memo.- 4750, 1996.

[4] S.J Katzberg, J.L. Garrison, N.C. Coffey, and H.R. Kowitz, "Method and system for monitoring sea state using GPS," Application filed with the U.S. Patent and Trademark Office, 8 January, 1998.

[5] B. Lin, S.J. Katzberg, J.L. Garrison, and B. Wielicki, "The relationship between the GPS signals reflected from sea surface and the surface winds: Modeling results and comparisons with aircraft measurements," J. Geophys. Res., Vol., 104(C9), pp.20,713-20,727, 1999.

[6] S.F. Clifford, V.I. Tatarskii, A.G. Voronovich, and V.U. Zavorotny, "GPS sounding of ocean surface waves: theoretical assessment," In Proc. Int. Geosci. and Remote Sens. Symp. (IGARSS), Vol. IV, Seattle, USA, pp. 2005-2007, 1999.

[7] V.U Zavorotny and A.G. Voronovich, "Scattering of GPS signals from the ocean with wind remote sensing application," IEEE Trans Geosci. Remote Sens., Vol. 38, No. 2, pp.951-964, 2000.

[8] V.U. Zavorotny and A.G. Voronovich, "Bistatic radar scattering from an ocean surface in the small-slope approximation." in the Proceedings of the IEEE International Geoscience and Remote Sensing Symposium: Remote Sensing of the System Earth - A Challenge for the 21 st Century, 99CH36293, pp. 24192421, IEEE, Piscataway, N. J., 1999.

[9] A. Komjathy, V.U. Zavorotny, and J.L. Garrison, "GPS: a new tool for ocean science," GPS World, Vol. 10, No. 4 , pp. $50-56,1999$.

[10] A. Komjathy, V.U. Zavorotny, P. Axelrad, G.H. Born and J.L. Garrison, "GPS signal scattering from sea surface: wind speed retrieval using experimental data and theoretical model," J. Remote Sens. Env., 2000 (in press).

[11] M.E. Shohr, "Field observations and model calculations of dielectric properties of Arctic sea ice in the microwave C-band," IEEE Trans. on Geosci and Remote Sens., Vol. 36, No. 2, pp.463-478, 1998.

[12] GEC Plessey Semiconductors, Global Positioning Products Handbook, 1996. 